\title{
Comunidades de prática e construção identitária de formadores de professores em um programa de formação continuada
}

\author{
Communities of practice and identity \\ construction of teacher educators in a \\ continuing teacher education program
}

\author{
Francisco Carlos Fogaça* \\ Universidade Federal do Paraná \\ Curitiba, Paraná / Brasil \\ Regina Célia Halu** \\ Universidade Federal do Paraná \\ Curitiba, Paraná / Brasil
}

\begin{abstract}
RESUMO: Este artigo é parte de uma pesquisa que procura investigar os efeitos que um programa de formação de professores pode ter tido na construção da identidade de professores universitários atuando em cursos de Letras, e que dele participaram como orientadores. Trata-se do Programa de Desenvolvimento Educacional (PDE), promovido pela Secretaria de Educação do Estado do Paraná (Seed-PR), para professores de escolas estaduais. Como referencial teórico, utilizamos o conceito de comunidades de prática ligando-o aos conceitos de comunidades imaginadas, identidade e investimento. Examinamos as trajetórias de dois professores universitários e como suas identidades são impactadas pelo processo de orientação no programa PDE, por meio de entrevistas semiestruturadas e um questionário. Os resultados mostram posições divergentes, que se relacionam com formas de alinhamento, imaginação e engajamento.
\end{abstract}

PALAVRAS-CHAVE: identidade profissional; comunidades de prática; comunidades imaginadas; investimento.

\footnotetext{
**fcfogaca@gmail.com

**reghalu@gmail.com
} 


\begin{abstract}
This article is part of a research project which investigates the effects of a teacher education program on the identity constructions of university professors who acted as advisors in the program. The Educational Development Program (Programa de Desenvolvimento Educacional - PDE) is provided by the Paraná State Department of Education (Seed-PR) to public school teachers. We draw on the concept of communities of practice, and the idea of imagined communities and investment. We analyzed the trajectories of two university teachers, and how their identities are impacted by the advisory process in the PDE program, through semi-structured interviews and a questionnaire. Results show diverging positions, which are related to different forms of alignment, imagination, and engagement.
\end{abstract}

KEYWORDS: professional identity; communities of practice; imagined communities; investment.

\title{
1 Introdução
}

Nas últimas décadas, houve grandes mudanças epistemológicas na Linguística Aplicada (LA) e em teorias de aquisição de línguas, sobretudo no que foi chamado de virada sociocultural (BLOCK, 2003). A LA passou a ser entendida não apenas como uma área aplicadora de teorias oriundas de pesquisas da Linguística, mas também como produtora de teorias. $\mathrm{Na}$ área de formação de professores de línguas, tais mudanças acompanharam o movimento reflexivo (SCHÖN, 1983; WALLACE, 1991; ZEICHNER; LISTON, 1996; RICHARDS; LOCKHART, 1994, para citar apenas alguns autores), assim como as propostas a partir de uma perspectiva pós-estruturalista e pós-moderna, especialmente no âmbito nacional (MARTINEZ, 2007; HALU, 2010; DUBOC, 2012), que passaram a considerar os professores de línguas também como produtores de conhecimento, não apenas aplicadores de teorias determinadas por outros. No contexto da formação de professores de línguas, o ensino passou a ser visto como um processo dialógico e situado de coconstrução de conhecimento, que emerge da participação em contextos e práticas socioculturais (JOHNSON, 2001, 2009, 2016). Dessa forma, entendemos a formação de professores de línguas como práticas contextualizadas, que surgem de processos de interação social em comunidades culturais onde tais práticas ocorrem (a escola, a comunidade, o bairro etc.). O conceito de Comunidades de Prática (CP) (LAVE; WENGER, 1991; WENGER, 1998a), nesse sentido, pode trazer importantes elementos para entendermos como os professores se desenvolvem (aprendem) em práticas situadas. 
Diversos trabalhos no Brasil abordam a formação docente, tanto inicial como continuada, sob a ótica das Comunidades de Prática (PERIN, 2009; HALU, 2010; CALVO, 2013; CALVO et al., 2014; MOSER, 2010; BOHN, 2010; SANTOS, 2015; RAMOS, 2011; entre outros). Trata-se de um referencial teórico que fornece um conjunto de ferramentas conceituais adequadas para examinar, entre outros aspectos, a formação identitária de profissionais que se aglutinam em função de objetivos comuns por meio da construção de um repertório de práticas sociais. Permite discutir as diferentes trajetórias dos participantes, respeitando as várias formas de participação. O conceito de participação periférica legítima em comunidades de prática (LAVE; WENGER, 1991, p. 35-36) permite interpretar de forma densa a participação e a trajetória dos participantes dentro das comunidades fora das dicotomias completa/ incompleta (como se todos tivessem de vir a exercer um conjunto geral e finito de funções) e centro/ periferia (como se houvesse apenas as opções de caminhar para um centro idealizado da comunidade ou para fora dele). É também um conceito que permite explorar as relações de poder que se formam e se modificam dentro de uma comunidade:

[c]omo um lugar no qual um participante se movimenta em direção a uma participação mais intensiva, a periferalidade é uma posição empoderadora. Como um lugar no qual um participante é impedido de participar mais plenamente - o que é feito frequentemente de forma legítima, da perspectiva mais ampla da sociedade em geral - é uma posição desempoderadora. Além disso, periferalidade legítima pode ser uma posição na articulação de comunidades relacionadas. Nesse sentido, ela mesma pode ser uma fonte de poder ou de falta de poder, ao permitir ou impedir articulação e intercâmbio entre comunidades de prática. (LAVE; WENGER, 1991, p. 36, tradução nossa) ${ }^{1}$

A partir dessas considerações iniciais, este trabalho é um recorte de uma pesquisa sobre o programa PDE e seus impactos na formação de professores e formadores de professores no estado do Paraná, sobretudo

\footnotetext{
${ }^{1}$ Texto original: "As a place in which one moves toward more-intensive participation, peripherality is an empowering position. As a place in which one is kept from participating more fully - often legitimately, from the broader perspective of society at large - it is a disempowering position. Beyond that, legitimate peripherality can be a position at the articulation of related communities. In this sense, it can itself be a source of power or powerlessness, in affording or preventing articulation and interchange among communities of practice".
} 
em suas identidades e trajetórias profissionais. ${ }^{2} \mathrm{O}$ PDE é abordado em diversas pesquisas, teses e dissertações (como em RAMOS, 2011; POSSI, 2012; AUDI, 2010; STEIN, 2015; CANAZART, 2015; GIMENEZ et al., 2015, para citar algumas), não somente na área de estudos da linguagem, mas também em outras disciplinas. A comunidade de professores participantes do programa PDE, tem igualmente produzido dezenas de trabalhos de conclusão em forma de relatos de experiências, disponibilizados e compartilhados pelo website da Seed. ${ }^{3}$

Neste artigo, apresentamos inicialmente um panorama do PDE, sua concepção de formação continuada e sua organização. Em seguida, trazemos conceitos teóricos que embasam a análise dos dados que geramos, tais como: comunidades de prática (LAVE; WENGER, 1991; WENGER, 1998a, 1998b); identidade (WENGER, 1998a; NORTON, 2013); comunidades imaginadas (ANDERSON, 1991; WENGER, 1998a; NORTON, 2013); e investimento (NORTON, 2013). Após a exposição e discussão de tais conceitos, apresentamos a metodologia da pesquisa e analisamos a construção das identidades de dois professores orientadores do programa PDE, a partir de entrevistas realizadas. Por fim, tecemos considerações finais sobre a pesquisa.

\section{O programa de desenvolvimento educacional (Seed-PR)}

O Programa de Desenvolvimento Educacional (PDE), ${ }^{4}$ promovido pela Secretaria Estadual de Educação do Paraná (Seed) desde 2007, é uma

\footnotetext{
${ }^{2}$ Este trabalho é resultado das atividades do grupo de pesquisas Formação de Professores em Línguas Estrangeiras, da Universidade Federal do Paraná.

${ }^{3}$ Seed/PDE: http://bit.ly/2rhYvDi

${ }^{4}$ Conforme página oficial do Programa, “[o] PDE é uma política pública de Estado regulamentado pela Lei Complementar no 130, de 14 de julho de 2010, que estabelece o diálogo entre os professores do ensino superior e os da educação básica, através de atividades teórico-práticas orientadas, tendo como resultado a produção de conhecimento e mudanças qualitativas na prática escolar da escola pública paranaense. O Programa de Desenvolvimento Educacional - PDE, integrado às atividades da formação continuada em educação, disciplina a promoção do professor para o nível III da carreira, conforme previsto no "Plano de carreira do magistério estadual", Lei Complementar no 103, de 15 de março de 2004. O objetivo do PDE é proporcionar aos professores da rede pública estadual subsídios teórico-metodológicos para o desenvolvimento de ações educacionais sistematizadas, e que resultem em redimensionamento de sua prática" (http://bit.ly/2qMeZCk).
} 
política pública que estabelece o diálogo entre os professores da educação superior e os da educação básica. O Programa tem duração de dois anos, sendo que no primeiro ano o professor participante obtém um afastamento de sala de aula, para que possa estudar e desenvolver atividades teóricopráticas.

A universidade pública parceira oferece cursos específicos de formação aos professores participantes, tais como metodologia para o ensino de línguas, aulas de língua estrangeira e cursos na área da educação em geral. Durante esse período, os mesmos são orientados por um professor da universidade, que contribuirá com perspectivas teóricas para o desenvolvimento de atividades didáticas. No segundo ano, tais atividades são implementadas em sala de aula e compartilhadas por meio de outra atividade do programa, o Grupo de Trabalho em Rede (GTR), que propõe uma interação a distância do professor PDE com demais professores da rede pública estadual, por meio da plataforma Moodle. Um dos objetivos é disseminar os projetos desenvolvidos pelos professores PDE a outros professores que ainda não participam diretamente do programa. Dessa forma, espera-se que mais professores, além dos que estão oficialmente em formação continuada, possam também ter um desenvolvimento profissional, mediante o acompanhamento dos projetos dos professores PDE.

A etapa final do programa inclui a elaboração de um relato de experiência (os documentos do PDE usam o termo artigo) que busca articular a teoria estudada, o processo de elaboração e implementação das atividades didáticas elaboradas, e também um relato do trabalho em rede, com as colaborações recebidas de outros professores. Não se trata exatamente de um artigo acadêmico nos moldes tradicionais, mas de um relato de toda a experiência vivida, com características teórico-práticas.

\section{0 que são comunidades de prática e quais características as distinguem de outras configurações sociais}

Wenger (1998a) afirma que as comunidades estão em todo lugar, mas sabe que, para que o conceito de comunidades de prática tenha alguma utilidade, ele não pode ser aplicado a toda e qualquer configuração social. Assim, enquanto ferramenta analítica, esse conceito é apresentado como uma categoria de nível intermediário: ele não se limita a uma atividade ou interação específica (como uma conversação) e também não cobre configurações amplas como instituições (como escolas, empresas) e sistemas 
(como nações e culturas). De acordo com Wenger (1998a, p. 125), nas primeiras não seria possível observar continuidades no tempo e entre as pessoas com relação aos empreendimentos e identidades dos quais são parte; quanto a acompanhar configurações maiores como comunidades, seriam as descontinuidades entre diversos espaços menores, com seus conjuntos de práticas, que seriam perdidas de vista. O surgimento de uma comunidade se daria dentro de configurações maiores, as quais Wenger trata como "constelações de práticas interconectadas" (1998a, p. 127, tradução nossa).

Uma comunidade de prática se desenvolveria, num esquema simplificado proposto por Wenger, conforme aparece na Figura 1 a seguir.

FIGURA 1 - Estágios de desenvolvimento de uma comunidade de prática

\section{Estágios de desenvolvimento}

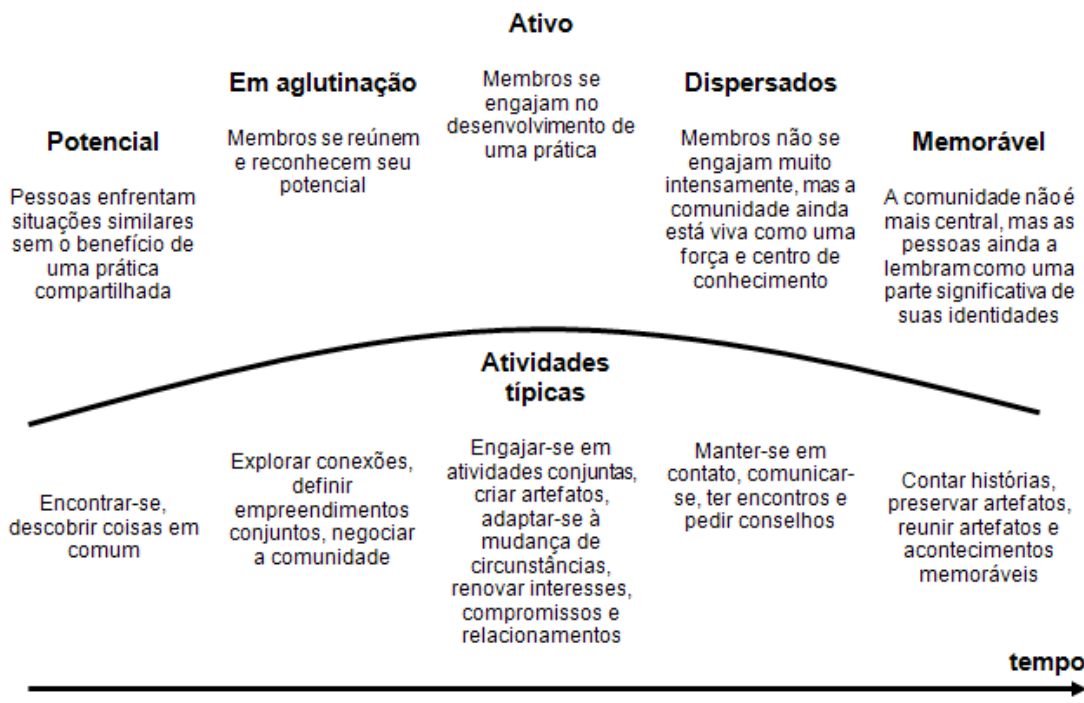

FONTE: Wenger, 1998 b (traduzido por HALU, 2010, p. 58)

Entretanto, esse quadro sucinto não se mantém estático como um modelo e deve ser visto como um ponto de partida para considerar as maneiras complexas como os participantes negociam e lutam por seus interesses e entendimentos nas práticas da comunidade, as quais se entrelaçam com práticas de configurações sociais mais amplas.

${ }^{5}$ Texto original: "[...] constellations of interconnected practices". 
Nos desdobramentos dos estudos sobre aprendizagem situada, especialmente na área da educação, a partir do final da década de 1990 (WENGER, 1998a; HODGES, 1998; ARDICHVILI; PAGE; WENTLING, 2003; LEONARD; LEONARD, 2003; O’DONNEL; TOBBELL, 2007; HANEDA, 2006), aprofundou-se o tratamento da natureza das comunidades de prática e da complexidade das relações entre seus participantes, reconhecendo e valorizando a presença de conflitos e suas diferentes formas de negociação, um processo contínuo com o qual uma comunidade precisa lidar para se manter como tal e garantir um processo de aprendizagem. A Figura 2 a seguir é um esboço resumido das questões envolvendo a presença de conflitos em comunidades de prática.

FIGURA 2 - Comunidades: tensão entre consenso e diversidade

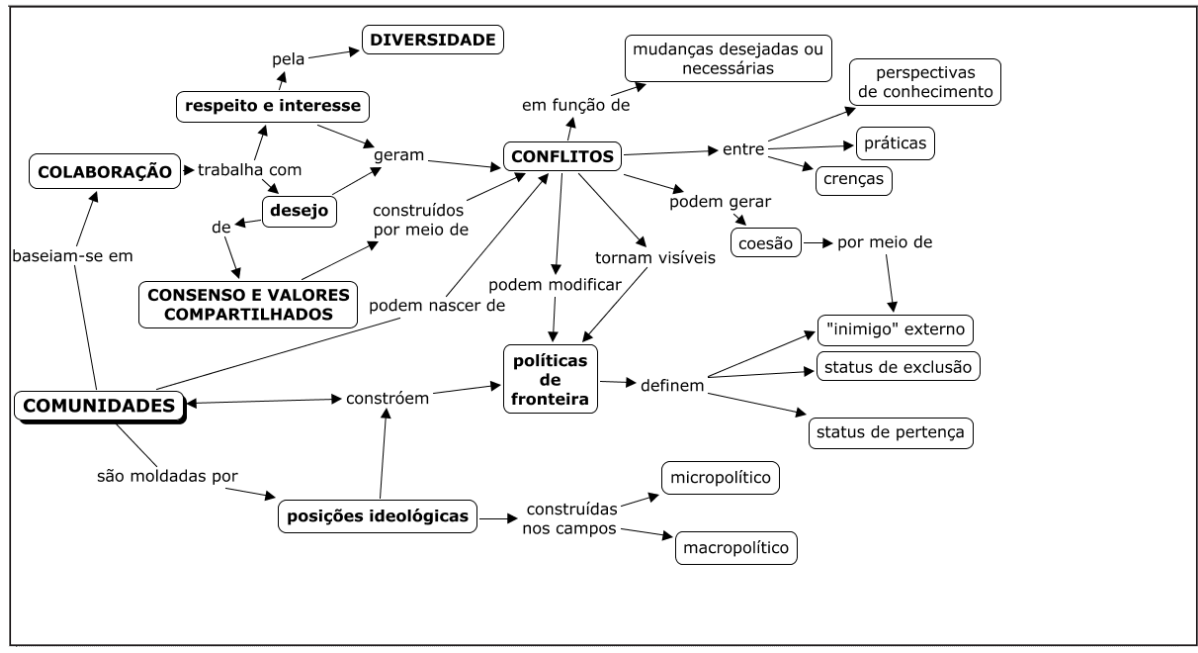

FONTE: (HALU, 2010, p. 59)

O trabalho em comunidades de prática baseia-se na colaboração. Esse trabalho vai depender de um desejo de consenso, crucial para seu surgimento e manutenção - um desejo de partilhar valores, de construir visões comuns e definir objetivos que são atingidos por meio de um trabalho conjunto. Entretanto, a comunidade vai depender também de uma percepção de que a diversidade precisa ser respeitada. A comunidade só irá adiante se houver não apenas respeito, mas também interesse pela diversidade, pelo que é diferente, pelas posições marginais e periféricas dentro da comunidade, pelas posições ocupadas por outras comunidades e as formas distintas como 
funcionam. Ou seja, a sobrevivência de uma comunidade vai depender da forma como seus participantes lidarão com essa tensão entre o desejo pelo consenso e o interesse pela diversidade.

É com base nessa visão de CPs que procuramos interpretar questões relativas à formação continuada dos professores universitários que vêm participando do PDE como orientadores. O programa PDE trouxe a oportunidade de se realizar um trabalho colaborativo entre professores nas escolas públicas estaduais e professores nas universidades públicas existentes no estado (federais e estaduais).

\section{Comunidades, identidades imaginadas e investimento}

Partindo do princípio de que a realidade é construída discursivamente (no e pelo discurso), podemos pensar que toda comunidade de prática tem uma dimensão imaginada, ou, em outras palavras, é construída discursivamente por cada um de seus membros em processos interativos de negociação de sentidos. Assim, embora possamos descrever uma CP em termos mais ou menos concretos de sua existência - participantes e formas de participação, práticas compartilhadas, instrumentos utilizados, objetivos comuns - cada um de seus membros atribui sentidos próprios a tal comunidade e forma uma ideia própria do que esta seja, que pode ser mais ou menos compartilhada pelo grupo. Contudo, Wenger (1998a) parece fazer uma distinção entre o que está ocorrendo de fato (no mesmo tempo e espaço), em uma atividade concreta, daquilo que imaginamos em outro tempo e espaço.

Wenger (1998a) pondera que os participantes de uma CP precisam usar sua imaginação para entender muitos dos processos e conexões que fazem parte de uma comunidade, mesmo que não tenham acesso e envolvimento direto com todas as suas práticas. Tais imagens (ou ideias) construídas por seus membros, de acordo com Wenger, não são menos significativas ou menos reais do que as práticas diárias da comunidade. $\mathrm{O}$ autor afirma que, para entendermos o processo de formação de identidades em uma CP, devemos considerar três formas de pertencimento a essa comunidade: a) imaginação; b) engajamento; c) alinhamento. A imaginação (WENGER, 1998a, p. 173, tradução nossa) tem a ver com "a criação de imagens do mundo, e a percepção de conexões no tempo e espaço, extrapolando 
nossa própria experiência". ${ }^{6} \mathrm{O}$ engajamento se refere ao "envolvimento mútuo em processos de negociação de significados". ${ }^{7}$ Já o alinhamento (WENGER, 1998a, p. 178-179, tradução nossa) “articula o tempo e o espaço para empreendimentos maiores, a fim de que os participantes se conectem pela coordenação de suas energias, ações e práticas". ${ }^{8}$ As três formas de pertencimento se articulam, mas não são necessariamente interdependentes. É possível, por exemplo, haver alinhamento sem que haja necessariamente um engajamento em uma determinada atividade.

O conceito de imaginação nos interessa mais de perto, por conta da concepção de comunidades imaginadas desenvolvida por Norton (2013), com base em Anderson (1991) e Wenger (1998a). Para Wenger, imaginação é o "processo de expansão de nós mesmos ao transcendermos nosso tempo e espaço e criarmos novas imagens do mundo e de nós mesmos" (p. 177). O autor dá como exemplos a ideia de olharmos para a semente de uma maçã e enxergarmos a árvore, ou tocarmos uma escala no piano, e imaginarmos uma sala de concertos. Em outras palavras, se refere à ideia de transcendermos o que está acontecendo em um determinado tempo e espaço, para pensarmos em outras possibilidades futuras.

No caso de um professor PDE, que se propõe a dar continuidade à sua formação, uma comunidade imaginada poderia ser uma comunidade de pesquisadores, como aquelas das quais os professores orientadores do programa fazem parte; ou, ainda, uma comunidade de professores estaduais que possam compartilhar suas práticas e aprendizagens desenvolvidas durante e após sua participação no programa, com seus colegas de trabalho. Em outros termos, talvez queiram uma inserção em um novo contexto (pesquisa acadêmica), ou uma maior inserção no próprio ambiente de trabalho - ou meramente subir de nível na carreira. Já os orientadores de professores PDE talvez possam imaginar uma comunidade de formadores de professores comprometida com o ensino público; ou talvez imaginem que um professor estadual participante do programa também queira fazer parte de sua comunidade de pesquisadores universitários. Essas são apenas

\footnotetext{
${ }^{6}$ Texto original: "creating images of the world and seeing connections through time and space by extrapolating from our own experience".

${ }^{7}$ Texto original: "active involvement in mutual processes of negotiation of meaning".

8 Texto original: "coordinating our energy and activities in order to fit within broader structures and contribute to broader enterprises".
} 
conjecturas, mas é possível que tais comunidades imaginadas possam influenciar o aprendizado e a construção das identidades tanto do orientador quanto do professor PDE - considerando que em uma prática educacional todos os participantes aprendem e se transformam.

Wenger não fala explicitamente sobre o papel da linguagem (discurso) na criação dessas imagens, ou ao fato de que mesmo as atividades mais comuns de uma comunidade de prática envolvem construções discursivas, uma vez que as pessoas engajadas em tais atividades atribuem sentidos próprios ao que estão realizando (FOUCAULT, 2000). Assim, podemos dizer que uma CP é sempre uma comunidade imaginada, já que tudo o que se refere a essa comunidade - os sentidos atribuídos a ela, suas práticas, seus membros, formas de pertencimento, identidades, papéis e trajetórias - são construídos discursivamente. Isso não significa dizer que a realidade não exista, ou que a comunidade seja mera fantasia, mas que ela é sempre perpassada por nossa (inter)subjetividade. Da mesma forma, podemos dizer que nossas identidades são construídas discursivamente, num processo dinâmico, fluido, conflituoso (por vezes), negociadas e produzidas em práticas discursivas.

Anderson (1991), que cunhou o termo comunidades imaginadas, se referia à ideia de uma "nação imaginada". Segundo o autor, mesmo na menor das nações, seus membros nunca irão conhecer a maioria das pessoas que dela fazem parte, ou mesmo ouvir a respeito delas. Mas, mesmo assim, a ideia de uma nação que vive em comunhão está presente no imaginário de seus membros - as pessoas imaginam pertencer a uma grande comunidade que partilha dos mesmos valores, da mesma língua, da mesma cultura.

Para Norton (2013, p. 8, tradução nossa) "ao nos imaginarmos ligados aos nossos conterrâneos no tempo e no espaço, podemos ter um sentido de comunidade com pessoas que não conhecemos ainda, mas talvez queiramos conhecer um dia". ${ }^{9}$ De acordo com a autora, um olhar voltado para comunidades imaginadas nos permite explorar como a filiação com tais comunidades afeta as trajetórias de aprendizagem de seus membros. Norton explica que tais comunidades incluem relacionamentos futuros, que existem somente na imaginação das pessoas. Tais comunidades, ainda segundo a

\footnotetext{
9 Texto original: "Thus, in imagining ourselves bonded with our fellow citizens across time and space, we can feel a sense of community with people we have not yet met, but perhaps hope to meet one day".
} 
pesquisadora (2013, p. 8), “não são menos reais que aquelas com as quais os aprendizes se engajam diariamente, e podem até mesmo ter um impacto maior nas suas ações e investimento" (tradução nossa). ${ }^{10}$

Em pesquisas com aprendizes de línguas estrangeiras, Norton (2013), Kanno e Norton (2003), Pavlenko e Norton (2007), Norton e Gao (2008) sugerem que comunidades imaginadas oferecem amplas oportunidades para o desenvolvimento de identidades dos aprendizes. Conforme Norton (2013, p. 2, tradução nossa), as identidades são influenciadas "por práticas comuns a instituições, tais como lares, escolas e locais de trabalho, bem como os recursos disponíveis, sejam eles materiais ou simbólicos". ${ }^{11}$ Ao analisarmos tais práticas e recursos, e como os aprendizes têm acesso a eles, podemos entender como suas identidades são produzidas e negociadas. Contudo, pondera a autora (2013, p. 3, tradução nossa), "por meio da agência humana os aprendizes que têm dificuldades de falar a partir de uma determinada posição identitária podem conseguir modificar seu relacionamento com os demais membros da comunidade, o que lhes permitiria falar, ler, ou escrever a partir de uma posição identitária alternativa e mais empoderada", ${ }^{2}$ alcançando melhores resultados de aprendizagem.

As possibilidades futuras e as comunidades imaginadas influenciam a forma como Wenger (1998a) e Norton (2013) entendem o conceito de identidade. Norton (2013, p 45, tradução nossa) afirma que identidade se refere "a como uma pessoa percebe seu relacionamento com o mundo, como esse relacionamento é construído no tempo e no espaço, e como a pessoa vê suas possibilidades futuras". ${ }^{13}$ Ou seja, tanto as relações já construídas em comunidades existentes, como aquelas que podem vir a

\footnotetext{
${ }^{10}$ Texto original: "These imagined communities are no less real than the ones in which learners have daily engagement and might even have a stronger impact on their current actions and investment".

11 Texto original: "This suggests that identity is influenced by practices common to institutions such as homes, schools and workplaces, as well as available resources, whether they are symbolic or material".

${ }^{12}$ Texto original: "Through human agency, language learners who struggle to speak from one identity position may be able to reframe their relationship with others and claim alternative, more powerful identities from which to speak, read or write".

${ }^{13}$ Texto original: "[h] ow a person understands his or her relationship to the world, how that relationship is constructed across time and space, and how the person understands possibilities for the future".
} 
existir, contribuem para a formação da identidade de uma pessoa. Dessa forma, o que alguém deseja ser em um espaço-tempo futuro (e as relações que pretende estabelecer em situações imaginadas) já faz parte de sua identidade e influencia diretamente o investimento que essa pessoa faz em seus empreendimentos.

Norton (2013) explica que o conceito de investimento utilizado por ela complementa e amplia a noção psicológica de motivação (GARDNER; LAMBERT, 1972), sobretudo no aprendizado de uma língua estrangeira. Tal noção tradicional distingue motivação instrumental e motivação integrativa: a primeira seria uma motivação utilitária, como obter um cargo melhor no trabalho, ou mesmo um novo emprego; a segunda seria o desejo de integrar-se em uma comunidade que fala determinada L2. ${ }^{14}$ Para a autora, no entanto, a noção de investimento está diretamente ligada à de identidade. Um aprendiz pode estar altamente motivado a aprender uma L2, e ainda assim fazer um investimento pequeno para tal fim, devido ao contexto de aprendizagem: a comunidade pode ser racista, homofóbica, preconceituosa, sexista, elitista etc., e o aprendiz sentir-se discriminado e incapaz de ter uma participação satisfatória, que valha à pena o investimento.

Enquanto motivação é um construto psicológico, investimento é um construto sociológico. Nas palavras de Darvin e Norton (2015, p. 37, tradução nossa), "enquanto construtos de motivação geralmente consideram que um indivíduo tenha uma identidade coerente e unitária, com características pessoais específicas, a noção de investimento considera o aprendiz como um sujeito social com uma identidade complexa, que muda no tempo e no espaço, e é reproduzida em uma interação social". ${ }^{15}$ Para esses autores, a identidade é múltipla, fluida e está em constantes conflitos. Assim, negociações de poder em diversos contextos vão determinar o quanto alguém vai ou não se propor a fazer um investimento, que também é complexo e contraditório, assim como a identidade.

${ }^{14} \mathrm{O}$ construto de motivação tem sido muito ampliado, desde que Gardner e Lambert (1972) conceituaram motivação integrativa e instrumental no aprendizado de línguas (DÖRNYEI, 1994; BROWN, 1990, 1994; WILLIAMS, 1994; GU, 2009, entre outros).

15 Texto original: "While constructs of motivation frequently view the individual as having a unitary and coherent identity with specific character traits, investment regards the learner as a social being with a complex identity that changes across time and space and is reproduced in social interaction." 
A ideia de investimento (NORTON, 2013) foi inspirada em Bourdieu (BOURDIEU, 1991; BOURDIEU; PASSERON, 1977), em suas noções de capital cultural e poder social. Um aprendiz que decide investir em um determinado aprendizado pode pressupor que vá adquirir diversos recursos materiais, ou capital econômico (i.e. dinheiro, um carro novo etc.), recursos simbólicos, ou capital simbólico (i.e. prestígio, honra, status), e recursos culturais, ou capital cultural (i.e. conhecimento, qualificação técnica, um novo idioma), os quais irão aumentar seu poder social. Uma forma de capital pode se converter em outra: uma qualificação educacional pode se converter em um emprego mais rentável e, por consequência, em mais status. Seja qual for a forma de capital buscada, existem implicações em relação a possibilidades futuras e à participação ou não em determinadas comunidades imaginadas. Tais possibilidades podem servir como elementos motivadores, mas é o investimento a ser feito que vai possibilitar a obtenção de determinadas formas de capital.

As noções de comunidades de prática, comunidades imaginadas, identidade e investimento discutidas neste artigo irão orientar a análise. A seguir, discutimos os dados obtidos por meio de questionários e entrevistas de dois orientadores do programa PDE, professores de duas universidades públicas do estado do Paraná: Carlos e Lúcia (nomes fictícios).

\section{Pesquisando a formação da identidade do professor orientador do programa PDE}

Esta pesquisa é de cunho qualitativo-interpretativista, entendendo que a realidade é uma construção discursiva, ou seja, perpassada por nossa subjetividade. Não acreditamos na neutralidade científica, e nos posicionamos como sujeitos interpretativos que criam sentidos a partir dos dados gerados. Ou seja, o olhar do pesquisador estará sempre presente, na tentativa de dar coerência aos sentidos produzidos durante a pesquisa.

Conforme mencionado anteriormente, este artigo é um recorte de uma pesquisa maior que investiga a construção das identidades de professores orientadores do Programa PDE. Para tanto, no segundo semestre de 2016, solicitamos que cada um dos dez sujeitos da pesquisa respondesse a um questionário para determinar o perfil dos participantes (ver Tabela 1 , mais adiante).

Além do questionário, realizamos uma entrevista semiestruturada com cada sujeito, com as seguintes questões: 1) Como foi sua experiência/ 
atuação no PDE na área de língua inglesa? Faça um breve relato sobre isso; 2) Das diferentes formas de participação no PDE, o que você considera mais relevante para o professor PDE e por quê? 3) Você acompanhou a implementação do projeto na escola? (avalie pontos positivos e negativos, se houver). Se não acompanhou, por quê? 4) Que diferenças você consegue perceber em relação a sua identidade como professor(a) de língua inglesa da universidade antes e depois do PDE? A participação no programa modificou alguma coisa na percepção que você tem de si mesmo(a)? 5) Como essas diferenças impactam ou impactaram sua forma de trabalhar com o ensino e a aprendizagem de língua inglesa na universidade? 6) Como você avalia a sua atuação como orientadora no PDE? Há algo que poderia ter sido diferente? Como? 7) Na sua percepção, quais os impactos que o programa tem na formação do professor, nas escolas e na sala de aula?

As entrevistas foram transcritas e analisadas em relação ao seu conteúdo. Em alguns casos, foi dada a opção aos participantes de responderem por escrito às questões guias da entrevista. Nesse recorte, no entanto, vamos abordar apenas as percepções de dois participantes, Carlos e Lúcia, por serem exemplos contrastantes. A entrevista com Carlos foi gravada e transcrita, Lúcia preferiu responder as perguntas por escrito; enquanto a entrevista com Carlos foi semiestruturada, dando margem a mais questionamentos e esclarecimentos, Lúcia deu respostas mais sucintas. A escolha desses dois sujeitos se deu por conta das discrepâncias entre suas respostas, incluindo percepções muito diferentes em relação ao processo de orientação no programa PDE. Apresentamos na Tabela 1, a seguir, dados sobre o perfil de cada participante.

Carlos e Lúcia possuem perfil um pouco diferente um do outro em relação a sua atuação na área de formação de professores em geral, experiência de trabalho, experiência com orientação de professores PDE e também com orientação de projetos na pós-graduação. Enquanto o primeiro tem mais experiência tanto como professor universitário como também em relação ao número de projetos PDE orientados, a segunda está iniciando sua carreira em uma universidade pública, após ter completado seu doutorado. Além disso, começou a atuar na pós-graduação e no PDE quase simultaneamente. 
TABELA 1 - Perfil dos sujeitos de pesquisa

\begin{tabular}{l|c|c}
\hline & Carlos & Lúcia \\
\hline Há quanto tempo orienta professores PDE & De 2008 a 2013 & De 2013 a 2014 \\
\hline Quantos orientandos já teve & 06 & $\begin{array}{c}\text { 01 completo } \\
\text { 02 incompletos }\end{array}$ \\
\hline $\begin{array}{l}\text { Há quanto tempo trabalha com formação } \\
\text { de continuada professores de línguas na } \\
\text { universidade }\end{array}$ & 12 anos & 02 anos \\
\hline Atuação como professor(a) de escola publica & Nunca & 01 ano \\
\hline Há quanto tempo é professor universitário & 12 anos & 03 anos \\
\hline $\begin{array}{l}\text { Desenvolve pesquisa na área de formação de } \\
\text { professores }\end{array}$ & Sim & Sim \\
\hline Atuação na pós-graduação & Sim anos & Não \\
\hline $\begin{array}{l}\text { Orientação de projetos na pós-graduação na } \\
\text { área de formação de professores }\end{array}$ & & \\
\hline
\end{tabular}

\subsection{A percepção de Carlos}

A trajetória de Carlos como orientador PDE teve diversas etapas. Inicialmente, ele parece entender que como são os professores participantes do PDE que vêm até a universidade para sua formação continuada - numa perspectiva tradicional de formação -, eles queiram participar de sua comunidade acadêmico-científica (ver fala de Carlos, a seguir). Também parece pressupor que, ao fazerem parte dessa comunidade que ele imagina, os professores PDE passem a atuar como participantes periféricos legítimos de tal comunidade (LAVE; WENGER, 1991). A participação periférica em uma comunidade, tal como sugerem esses autores, pressupõe a atuação em atividades de iniciação às práticas da comunidade (como geralmente fazem os novatos), para que possam eventualmente atingir a condição de participantes plenos. Isso implicaria a iniciação à pesquisa, a introdução ao discurso acadêmico e a familiarização com o repertório de práticas e instrumentos utilizados pela comunidade. Carlos diz ter pensado que a orientação de um professor PDE seria semelhante à orientação de um mestrado acadêmico, com a produção de um texto científico nos mesmos moldes. É possível que sua iniciação como orientador do programa PDE tenha coincidido com as primeiras orientações de mestrado, como professor 
no programa de pós-graduação da universidade, e que tal prática tenha influenciado suas percepções em relação ao PDE. A seguir, Carlos nos fala de suas dificuldades em entender os propósitos desse programa de formação continuada:

Inicialmente foi um pouco difícil entender qual que era o propósito do PDE. Eu tinha na cabeça que era mais ou menos um tipo de orientação, como a orientação do mestrado, e o tipo de produção também seria parecido. [...] Então, eu senti que pra eles é importante poder voltar à universidade e ter essas aulas e poder encontrar outros professores, se sentir talvez como um grupo... não sei. (Carlos)

Carlos parece pressupor que, como o movimento realizado foi de aproximação dos professores estaduais em direção à universidade (e não o contrário), são eles que devem fazer o investimento para participarem de tal comunidade (NORTON, 2013). No entanto, Carlos parece fazer uma confissão de culpa em relação a não ter conhecido as escolas estaduais onde seus orientandos atuavam, assumindo um tom quase confessional. Trata-se de um olhar retrospectivo em relação a sua própria prática como orientador, ao especular sobre como teria sido se tivesse "acompanhado de perto, se [...] pudesse ter assistido a alguma aula”, como podemos ver na narrativa a seguir:

Eu acho que eu tive um envolvimento razoável, mas foi até certo ponto, né. Eu nunca saí da universidade e da minha sala em termos de orientação [...] Eu não acompanhei diretamente a implementação do projeto na escola. Embora tenha sido convidado algumas vezes pra ir até a escola, eu não fui, eu confesso. Eu soube da implementação através dos professores, né, através do que eles me contavam, de como tinha ido a aula, do resultado [...]. Agora, teria sido diferente se eu pudesse ter acompanhado de perto, se eu pudesse ter assistido alguma aula... ou, enfim, estado mais presente. (Carlos)

Tal reflexão só foi possível após um processo de interação e negociação com seus orientandos ao longo do tempo, embora só tenha ocorrido dois anos após ter concluído suas últimas orientações de professores PDE. Há uma mudança no entendimento inicial, à medida que as identidades e as comunidades imaginadas são negociadas ao longo desse processo de orientação: Carlos passou a ver os professores estaduais não mais como membros potenciais, ou participantes periféricos legítimos (LAVE; WENGER, 1991) de sua comunidade acadêmico-científica, mas como 
participantes de outra comunidade profissional. Carlos parece lamentar o investimento não realizado de sua parte, na medida em que diz que seu envolvimento tenha sido razoável, mas que "foi até certo ponto".

O tom confessional de Carlos prossegue quando reconhece que poderia ter se envolvido mais nos GTRs, que é justamente quando os professores participantes do PDE podem disseminar suas descobertas e o desenvolvimento de suas atividades didáticas com outros colegas de profissão, por meio da plataforma Moodle. Como vimos anteriormente, o GTR é uma espécie de curso on-line oferecido para outros professores de escola pública, coordenado pelo professor PDE. O orientador pode sugerir perguntas e temas para discussão no GTR e acompanhar o envolvimento dos participantes do curso. De fato, olhar para trás e perceber o que poderia ter sido (e não foi) é uma forma de transformação e de percepção de seu trabalho como formador de professores e, portanto, de sua identidade profissional.

Eu acompanhei um pouco de longe esses trabalhos do GTR. Eu confesso que talvez eu devesse ter entrado mais nos... ahm... ou pedido acesso à plataforma Moodle pra poder ver e acompanhar o andamento, né. Eu vi os resultados a partir dos relatos, porque em todos os trabalhos escritos, na produção do artigo, os professores colocavam alguma coisa de resultados em relação ao GTR, como foi esse compartilhamento do projeto, e as ideias e sugestões que receberam. (Carlos)

A produção de um texto acadêmico por parte dos professores PDE era inicialmente vista por Carlos como muito importante nesse processo de orientação dentro do programa. Tal entendimento se devia, possivelmente, ao pressuposto de que se tratava da integração desses professores (supostamente participantes periféricos legítimos) em sua comunidade de prática. A seguir, Carlos diz ter percebido que a produção do artigo (o relato obrigatório no último estágio do PDE) seria menos relevante do que a forma como o professor PDE iria implementar as atividades na escola e compartilhá-las com seus pares.

Em relação ao artigo, na minha opinião, talvez seja a parte menos importante, né. Eu acho que o que acontece dentro da escola talvez seja mais importante, e é justamente a parte em que eu confesso não ter tido acesso. Não acompanhei, não sei como foi feita essa... essa disseminação das ideias, ou do PDE, compartilhar com outros colegas. Eu não sei o que acontece a partir daí. Acho que é mais ou menos isso. (Carlos) 
No entanto, a constituição de sua identidade de formador de professores passa também pela compreensão do que Wenger (1998a, p. 153) chama de "trajetórias de aprendizagem", que podem ser múltiplas, convergentes ou divergentes. São as trajetórias de aprendizagem que levam orientadores e professores PDE ao contato entre suas comunidades de prática (imaginadas ou não). Nas palavras de Wenger (1998a, p. 159, tradução nossa) "uma identidade é mais do que uma única trajetória; ao contrário, deveria ser vista como o nexo de nosso pertencimento a várias comunidades" ${ }^{16}$ Por vezes, tais trajetórias são conflitantes e divergentes, outras vezes convergem para pontos comuns. Isso não significa que uma identidade seja uma unidade, mas também não simplesmente composta de fragmentos. Para Wenger (1998a, p.159, tradução nossa) "a ideia de nexo acrescenta multiplicidade à noção de trajetória. O nexo não unifica as trajetórias específicas que formamos em nossas várias comunidades de prática, mas tampouco decompõe nossa identidade em trajetórias distintas em cada comunidade". ${ }^{17}$

Como as identidades são complexas, fluidas e mudam no tempo e no espaço (WENGER, 1998a; NORTON, 2013; DARVIN; NORTON, 2015), parece ser difícil para Carlos perceber como se deu esse processo de transformação de sua identidade profissional. São transformações sutis, nem sempre percebidas, conforme nos diz em sua entrevista.

É... essa é uma pergunta bem difícil, né, porque essas mudanças em relação à... à percepção de si mesmo profissionalmente e em relação à identidade não são coisas mensuráveis, a menos que você faça um exercício reflexivo, e assim mesmo é difícil medir né? (Carlos)

No entanto, ele se vê como formador de professores, e entender melhor o seu papel como formador o faz se sentir mais relevante. Podemos constatar, também, que Carlos percebe a importância tanto da formação inicial quanto da formação continuada em seu trabalho como formador,

\footnotetext{
${ }^{16}$ Texto original: "An identity is thus more than just a single trajectory; instead, it should be viewed as a nexus of multimembership."

${ }^{17}$ Texto original: "This notion of nexus adds multiplicity to the notion of trajectory. A nexus does not merge the specific trajectories we form in our various communities of practice into one; but neither does it decompose our identity into distinct trajectories in each community."
} 
embora esta última ocorra com menor frequência. Ao afirmar que sentir-se mais próximo da realidade da escola pública faz seu trabalho parecer mais importante, temos a ideia de que ele percebe um ganho de capital simbólico, que possivelmente tenha feito o investimento realizado valer a pena.

$\mathrm{Eu}$ acho que profissionalmente acrescentou. Eu não saberia dizer o quanto, nem como, mas me sentir mais próximo da realidade da escola pública faz o meu trabalho parecer mais importante, já que eu me vejo como formador de professores. E, dentro do curso de Letras, esse papel se dá muito mais na formação inicial; a formação continuada acontece em oportunidades como essa... como o PDE. (Carlos)

Ele entende o papel das práticas sociais/ discursivas no desenvolvimento de sua identidade profissional, assim como o papel do outro e das interações sociais. Reconhece que ao pensar no projeto do professor PDE, e de suas possibilidades de implementação no contexto escolar, acaba revendo suas próprias práticas e pressupostos teóricos. Carlos nos diz que

[...] de certa forma, toda a experiência de orientação traz um crescimento, né... pra gente, que orienta... porque é um aprendizado mútuo. Ao orientar os projetos, ao pesquisar sobre, digamos, a fundamentação teórica, ou pensar numa proposta de implementação de atividades didáticas de sala de aula, né, a gente acaba fazendo uma revisão dos próprios conceitos e... entendendo um pouco melhor aquilo que é possível e o que não é possível, talvez, dentro de uma realidade escolar específica. Ahm... e nada melhor do que o professor da sala de aula pra ter esse diálogo. (Carlos)

Entendemos que tal conflito de representações - em comunidades de prática e comunidades imaginadas - é parte do processo de construção da identidade de Carlos e gerador de desenvolvimento profissional (FOGAÇA, 2011; CRISTÓVÃO; FOGAÇA, 2008). Esse confronto de representações sobre a atividade do professor na escola pública e a revisão de conceitos teórico-práticos para a elaboração de uma proposta de implementação de atividades didáticas de sala de aula deflagra um processo de reconfiguração das representações e da identidade de Carlos. 


\subsection{A percepção de Lúcia}

As respostas de Lúcia trazem um desafio para nós, pesquisadoresparticipantes, que também refletimos sobre nossas participações no programa PDE como orientadores e fazemos uma avaliação relativamente positiva da experiência, não deixando de incorporar nela dificuldades e conflitos encontrados. Lúcia traz a experiência da frustração na sua participação como orientadora no PDE. Suas palavras iniciais apontam para uma avaliação negativa da experiência, deixando clara a frustração de expectativas:

Iniciei motivada, com o rigor necessário para um projeto de pesquisa de dois anos com produção de artigo ao final, mas passei a entender que os professores PDE, pelo menos os que estiveram sob minha orientação, não estão preparados para as exigências necessárias [dentro] de um modelo de pesquisa nos moldes do PDE. (Lúcia)

A referência a uma demanda de rigor que não é atendida, gerando frustração, vai aparecer novamente nas respostas, como no comentário que se segue:

A produção do artigo acaba sendo algo muito superficial, tendo em vista que o professor PDE, na maioria das vezes, não está acostumado ao rigor da produção científica, e os orientadores precisam ensinar como fazer um artigo primeiro e, depois, trabalhar muito nele para que fique algo razoável para a publicação. (Lúcia)

Além disso, quando Lúcia é questionada quanto ao impacto de sua experiência no PDE na sua identidade profissional (pergunta 4 da entrevista) sua resposta é categórica: “[...] não percebi mudança nem lá (professores) nem cá (minha)". Essa resposta é reforçada ao avaliar o impacto da experiência no PDE em sua forma de trabalhar com o ensino e aprendizagem de língua inglesa na universidade (pergunta 5 da entrevista): "como não percebi mudança, não percebi impacto".

Assim como no caso de Carlos, para abordar o posicionamento discursivo de Lúcia, é necessário retomar alguns aspectos da noção dinâmica de identidade que ancora nossa interpretação. A identidade, incluindo o conceito de identidade profissional, é temporal, e o trabalho de construção identitária é contínuo. A noção de identidade implica uma experiência de multipertencimento e um trabalho de reconciliação necessário para construir 
uma identidade através de fronteiras das diversas comunidades em que habita. Há, ainda, várias trajetórias possíveis dentro de uma comunidade (inbound, outbound, periférica, insider, limítrofes) que são desenhadas a partir de diferentes formas de participação e não participação (WENGER, 1998a).

Lúcia vem construindo uma longa trajetória dentro de uma comunidade de pesquisadores em Linguística, investindo em sua formação acadêmica (havia terminado seu doutorado recentemente). Um dos retornos desse investimento na sua formação acadêmica foi ter conseguido iniciar sua carreira como docente em uma universidade pública, contexto para o qual projetava sua identidade imaginada. A referência às "exigências do rigor científico" em seu discurso permite localizá-la na posição de pesquisadora universitária, compartilhando fortemente valores e concepções ligados à produção científica característica do trabalho realizado nos programas de pós-graduação.

A participação em programas de pós-graduação é de fato uma das facetas do docente universitário, juntamente com a docência na graduação. No entanto, entre os campos de atuação do professor universitário há ainda a extensão universitária, em que o programa PDE se insere. Não há preparação prévia do docente para atuação na extensão. O aprendizado se dá justamente pelo envolvimento em práticas extensionistas, as quais têm sido historicamente vistas dentro da academia como hierarquicamente inferiores às práticas de pesquisa.

O PDE é um programa que coloca vários desafios para o professor universitário, o mais importante deles sendo, talvez, o de aprender novas formas de produção de conhecimento por meio de um empreendimento conjunto entre professores do ensino básico e professores universitários. Nesse caso, um programa criado como política pública de formação continuada de professores pela Seed-PR, atrelado a um plano de carreira para o professor da educação básica - iniciativa praticamente única no Brasil. O programa depende da participação das universidades públicas do estado e coloca uma demanda sobre elas. Uma das possíveis formas de interpretar essa demanda é vê-la como um convite aos docentes universitários atuantes ou interessados em atuar na formação de professores do ensino básico, atuar em um programa com potencial para o desenvolvimento de diversas comunidades de prática.

Lúcia aceitou o convite procurando engajar-se no programa, mas investida de suas expectativas de pesquisa acadêmica. Foi a partir de sua trajetória como pesquisadora que ela procurou se engajar nas atividades 
de orientação de projetos do PDE, que são de cunho eminentemente pedagógicos, voltados principalmente para o repensar das práticas de sala de aula e para o planejamento e implementação de atividades novas ou alternativas. As professoras das escolas, em cada região do estado, também foram investidas de suas expectativas que variavam de acordo com o seu tempo de carreira, o engajamento na docência e na comunidade da escola e as reações frente a uma interrupção de um ano pelo menos na rotina de seu trabalho. O trabalho dentro do programa ainda tem a mediação de professores atuando nas coordenações em cada instituição de ensino superior (IES) envolvida. Juntos, todos esses profissionais precisam de tempo para, entre outros desafios, criar um compartilhamento de conceitos e ideias, um espaço em que vão negociando suas visões de mundo, alinhandoas a objetivos mais amplos do que os desenhos iniciais de suas trajetórias profissionais.

Um exemplo pode ser a leitura e as diferentes interpretações do documento síntese do Programa, um texto apresentado pronto pela Seed-PR tanto para os professores do estado como para os professores universitários. Foi nele que Lúcia encontrou o termo "artigo científico" como o produto esperado dos professores PDE ao final da última etapa do programa. E em torno do sentido desse termo, ao orientar professores participantes, ela experimentou muita frustração e, a partir desse sentimento, elaborou em seu discurso a negação de mudança tanto nela mesma quanto nos professores que orientou. No entanto, após essa experiência como docente atuando na formação continuada de professores da educação básica, a intensidade com que negou perceber mudança aponta para o que ainda está para ser desenhado: ela pode afastar-se do programa e intensificar suas atividades de pesquisa em Linguística; permanecer no programa com a mesma visão ou com visão diferente; ou, ainda, desempenhar outra função dentro do programa. Pode, também, vir a ressignificar a experiência mais tarde e explorar os conflitos vivenciados, reforçando o distanciamento ou permitindo a aproximação a essa ou outras comunidades.

Mesmo negando mudanças e impactos, ela ouviu o que os professores lhe diziam e que lhe incomodava, como no caso das cobranças que eram feitas aos professores PDE, os quais julgavam não estar de acordo com o que as escolas precisavam e o próprio programa propunha. Além disso, entrou em contato com pelo menos dois mundos para os quais sua trajetória profissional, centrada na pesquisa e na docência universitária, até então não oferecia muito espaço: a extensão universitária e a educação básica. 


\section{Considerações finais}

Assim como a formação dos professores participantes do programa de formação continuada PDE, o desenvolvimento dos professores formadores se dá numa perspectiva de aprendizagem situada (LAVE; WENGER, 1991; JOHNSON, 2001; 2009; 2016). Para Johnson (2001, p. 56, tradução nossa), "uma perspectiva socialmente situada de conhecimento entende os processos de aprendizagem como sendo negociados com as pessoas em práticas sociais, associadas com tipos particulares de atividades". ${ }^{18} \mathrm{Tal}$ perspectiva deve, segundo a pesquisadora, transformar o conhecimento, valores e crenças que os professores trazem consigo, para que possam ser construídos de fato nas salas de aula e nos contextos sociais onde atuam, ou em suas comunidades de prática. Entendemos que é no espaço da orientação, na relação com os orientandos, que se dá a construção de conhecimentos do professor orientador e o processo de reconfiguração de suas representações.

As identidades dos formadores de professores se constroem num processo de identificação e negociação (WENGER, 1998a) com as formas de pertencimento mencionadas anteriormente (engajamento, imaginação e alinhamento). No caso de Carlos, pudemos ver inicialmente a ideia de uma comunidade imaginada (NORTON, 2013), da qual o formador supunha que seus orientandos quisessem participar. Embora houvesse, em parte, um alinhamento com os objetivos do programa PDE - sobretudo quanto à ideia de uma formação continuada e à elaboração de projetos pedagógicos havia uma dissonância em relação aos objetivos reais do programa. Porém, esse alinhamento inicial foi importante para que o processo de identificação com o programa fosse negociado e coconstruído com seus orientandos. A imaginação, da mesma forma, foi negociada e construída discursivamente ao longo do processo de orientação, ao ponto de Carlos perceber que os participantes do programa pertenciam a outra comunidade com a qual interagiam e construíam suas identidades - e que talvez não quisessem fazer parte do meio acadêmico universitário. Carlos e seus orientandos identificaramse com as atividades propostas pelo PDE (em formas de engajamento). Contudo, esse engajamento não foi suficiente para fazer com que Carlos participasse da implementação das propostas pedagógicas nas escolas onde seus orientandos atuavam. Tais formas de identificação fizeram com que a participação no programa contribuísse para a construção da identidade de

\footnotetext{
18 Texto original: "A socially-situated view of knowledge argues that the processes of learning are negotiated with people in what they do, through experiences in the social practices associated with particular activities".
} 
Carlos, que reforçou sua percepção como formador de professores e lhe permitiu maior abertura para um contexto de ensino diferente do seu.

Já no caso de Lúcia, em suas primeiras experiências no programa, houve tempo apenas para que se estabelecesse um conflito entre suas expectativas e as dos professores que orientou, com consequente sensação de frustração. Interpretamos parte desse conflito como sendo devido ao seu alinhamento e longo investimento em uma comunidade de pesquisadores em Linguística. Ela aceitou o desafio de participar de um programa para o qual tinha tido pouca formação profissional, a atuação na área da extensão, em um programa voltado para a formação continuada de professores na escola pública. Estava, de fato, iniciando uma trajetória profissional que extrapolava sua trajetória como pesquisadora acadêmica e que exigiria o reconhecimento de que começava a atuar em outra comunidade, com outras premissas e valores em negociação. No ponto em que se encontrava quando da participação nesta pesquisa, houve discursivamente uma negação do impacto que sua experiência pode ter tido para ela e para seus orientandos. A própria intensidade da negação, entretanto, apontava para os conflitos que se instauraram: sua concepção de pesquisa e produção científica na academia e a visão dos professores da pesquisa com fins de transformação pedagógica nas escolas; sua valorização do "artigo científico" e a valorização da fase de implementação pedagógica pelos professores; a distância existente entre as trajetórias profissionais de orientadores e de professores; a dificuldade de abertura de negociação de sentidos entre ambas as partes; a distância e a hierarquia entre a universidade e a escola. A experiência de Lúcia expôs também o esforço exigido para a construção de identidade enquanto participamos de diversas comunidades, "um nexo de multipertencimento" (WENGER, 1998a, p. 159) que gera tensões.

Os exemplos de Carlos e Lúcia podem mostrar quão complexos e variados são os processos de identificação e negociação que vão construindo as identidades dos professores orientadores. A participação ou até mesmo um contato fronteiriço com outras comunidades e outros contextos criam tensões que podem levar a uma expansão ou modificação de suas representações, como no caso de Carlos, ou a uma intensificação das mesmas e impossibilidade momentânea de negociação, como no caso de Lúcia. Como expressa Wenger (1998a, p. 159), “a identidade não é uma unidade, tampouco é simplesmente fragmentada". ${ }^{19}$ Nos nossos nexos

${ }^{19}$ Texto original: "[...] identity is not a unity but neither is it simply fragmented." 
de participação, múltiplas trajetórias se cruzam e influenciam umas às outras, às vezes gerando demandas inconciliáveis entre algumas, às vezes proporcionando crescimento em várias delas.

É importante ressaltar a nossa percepção de que o investimento (NORTON, 2013; WENGER, 1998a), e também o não investimento, ocorreu em função do processo de identificação com as formas de pertencimento a uma comunidade, imaginada ou não. Entendemos que é justamente esse processo de identificação e negociação que possibilita o investimento. Em outras palavras, o investimento não ocorre simplesmente por uma ação consciente por parte dos membros de uma comunidade na busca de um capital simbólico, mas por um processo de identificação e negociação com as formas de pertencimento em uma comunidade, que pode ocorrer ou não. É esse processo de identificação, negociado a partir de relações de poder, que pode levar a um investimento.

Em relação a pesquisas futuras, podemos vislumbrar: a) a possibilidade de explorar a formação de identidades de professores de escola pública participantes do programa; b) uma análise da produção escrita dos professores PDE, que se dá em forma de relatos de experiência; c) o impacto do programa nas escolas, percebido tanto por professores formadores quanto pelos professores PDE; d) mudanças de crenças e de práticas de ensino dos professores universitários e/ ou dos professores PDE; e) o processo de implementação dos projetos nas escolas; f) o processo de compartilhamento dos projetos com colegas de profissão; g) a disseminação dos projetos por meio dos GTRs.

\section{Referências}

ANDERSON, B. Imagined communities: reflections on the origin and spread of nationalism. New York: Verso, 1991.

ARDICHVILI, A.; PAGE, V.; WENTLING, T. Motivation and barriers to participation in virtual knowledge-sharing communities of practice. Journal of Knowledge Management, Wagon Lane, v. 7, n. 1, p. 64-77, 2003.

AUDI, L. C. C. Eu me sinto responsável: os impactos do Programa de Desenvolvimento Educacional (PDE) sobre a formação de professores de inglês. 2010. 105 f. Dissertação (Mestrado em Estudos da Linguagem) - Universidade Estadual de Londrina, Londrina, 2010.

BLOCK, D. The social turn in second language acquisition. Edinburgh: Edinburgh University Press, 2003. 
BOHN, V. C. R. Comunidades de prática na formação docente: aprendendo a usar ferramentas da Web 2.0. 2010. 158 f. Dissertação (Mestrado em Linguística) Universidade Federal de Minas Gerais, Belo Horizonte, 2010.

BOURDIEU, P. Language and symbolic power. Cambridge: Polity Press, 1991.

BOURDIEU, P.; PASSERON, J. C. Reproduction in education, society, and culture. Thousand Oaks: Sage Publications, 1977.

BROWN, D. H. M\&Ms for language classrooms? Another look at motivation. In: ALATIS, J. E. GEORGETOWN UNIVERSITY ROUND TABLE ON LANGUAGE AND LINGUISTICS, 1990, Washington D.C. Proceedings... Washington D.C.: Georgetown University Press, p. 383-393, 1990.

BROWN, D. H. Teaching by principles: an interactive approach to language pedagogy. Englewood Cliffs: Prentice Hall, 1994.

CALVO, L. C. S. Reflexões sobre uma comunidade de prática constituida a partir das interações de formadoras de professores de inglês em um grupo de estudos. 2013. 191 f. Tese (Doutorado em Estudos da Linguagem) - Universidade Estadual de Londrina, Londrina, 2013.

CALVO, L. C. S. et al. Comunidades de prática: aspectos da formação de professores de línguas em foco. Campinas: Pontes Editores, 2014.

CANAZART, C. A. Efeitos de políticas de formação continuada na prática pedagógica de ensino de inglês: uma experiência de participação no PDE-PR. 2015. 180 f. Dissertação (Mestrado em Estudos da Linguagem) - Universidade Estadual de Londrina, Londrina, 2015.

CRISTOVÃO, V. L. L.; FOGAÇA, F. C. Desenvolvimento: um conceito constitutivo do gênero profissional docente. In: CRISTOVÃO, V. L. L. Estudos da Linguagem à luz do interacionismo sociodiscursivo. Londrina: UEL, 2008. p. 13-33.

DARVIN, R.; NORTON, B. Identity and a model of investment in applied linguistics. Annual Review of Applied Linguistics, Palo Alto, v. 35, p. 36-56, 2015.

DÖRNYEI, Z. Motivation and motivation in the foreign-language learning classroom. Modern Language Journal, Hoboken, v. 78, n. 3, p. 273-284, 1994.

DUBOC, A. P. M. Atitude curricular: letramentos críticos nas brechas da formação de professores de inglês. 2012. 246f. Tese (Doutorado em Estudos Linguísticos e Literários em Inglês) - Universidade de São Paulo, São Paulo, 2012.

FOGAÇA, F. C. Conflito e desenvolvimento: duas faces da mesma moeda. In: CRISTÓVÃO, V. L. L. (Org.). Atividade docente e desenvolvimento. Campinas: Pontes Editores, 2011. p. 91-98.

FOUCAULT, M. A arqueologia do saber. 6. ed. Rio de Janeiro: Martins Fontes, 2000. GARDNER, R. C.; LAMBERT, W. E. Attitudes and motivation in second language learning. Rowley: Newbury House, 1972. 
GIMENEZ, T. et al. Recontextualização pedagógica e políticas de formação continuada de professores de língua inglesa: o caso do PDE-PR. Ilha do Desterro, Santa Catarina, v. 68, n. 1, p. 61-74, 2015.

GU, M. The discursive Construction of second language learners' motivation: a multi-level perspective. Bern: Peter Lang, 2009.

HALU, R. C. Formação de formadoras de professoras de inglês em contexto de formação continuada (NAP-UFPR). 2010. 246 f. Tese (Doutorado em Letras) - Setor de Ciências Humanas, Letras e Artes, Universidade Federal do Paraná (UFPR), Curitiba, 2010.

HANEDA, M. Classrooms as communities of practice: a reevaluation. Tesol Quarterly, Hoboken, v. 40, n. 4, p. 807-817, 2006.

HODGES, D.C. Participation as dis-identification with/ in a community of practice. Mind, Culture, and Activity, Abingdon, v. 5, n. 4, p. 272-290, 1998.

JOHNSON, K. Teacher learning in second language teacher education: a sociallysituated perspective. Revista Brasileira de Linguística Aplicada, Belo Horizonte, v. 1, n. 1, p. 53-69, 2001.

JOHNSON, K. Second language teacher education: a sociocultural perspective. New York: Routledge, 2009.

JOHNSON, K. Language teacher education. In: HALL, G. (Ed.) Routledge handbook of English language teaching. New York: Routledge, 2016. p. 121-134.

KANNO, Y.; NORTON, B. Imagined communities and educational possibilities: introduction. Journal of Language, Identity and Education, Abingdon, v. 2, n. 4, p. 241 249, 2003.

LAVE, J.; WENGER, E. Situated learning: legitimate peripheral participation. Cambridge: Cambridge University Press, 1991.

LEONARD, L.; LEONARD, P. The continuing trouble with collaboration: teachers talk. Current Issues in Education, Arizona, v. 6, n. 15, 2003.

MARTINEZ, J. Z. Uma leitura sobre concep̧cões de língua e educação profissional de professores de língua inglesa. 2007. 154 f. Dissertação (Mestrado em Letras) Universidade Federal do Paraná, Curitiba, 2007.

MOSER, A. Formação docente em comunidades de prática. Revista Intersaberes, Curitiba, v. 5, n. 10, p.210-244, 2010.

NORTON, B. Identity and language learning. Bristol: Multilingual Matters, 2013.

NORTON, B.; GAO, Y. Identity, investment, and Chinese learners of English. Journal of Asian Pacific Communication, Amsterdam, v. 18. n. 1, p. 109-120, 2008. 
O'DONNEL, V. L.; TOBBELL, J. The transition of adult students to higher education: legitimate peripheral participation in a community of practice? Adult Education Quarterly, Thousand Oaks, v. 57, n. 4, p. 312-328, 2007.

PAVLENKO, A.; NORTON, B. Imagined communities, identity, and English language teaching. In: CUMMINS, J.; Davison, J. (Ed.). International handbook of English language teaching. New York: Springer, 2007. p. 669-680.

PERIN, J. Emergência e construção de uma comunidade de prática de formadores de professores de ingua inglesa. 2009. $264 \mathrm{f}$. Tese (Doutorado em Estudos da Linguagem) Universidade Estadual de Londrina, Londrina, 2009.

POSSI, E. H. B. Programa de Desenvolvimento Educacional - PDE/PR (2007-2009): um estudo sobre as transformações e permanências. 2012. 226 f. Dissertação (Mestrado em Educação) - Universidade Estadual de Londrina, Londrina, 2012.

RAMOS. S. M. Oprograma de desenvolvimento educacional do estado do Paraná e sua proposta de formação continuada: foco nos grupos de trabalho em rede. 2011. $264 \mathrm{f}$. (Doutorado em Estudos da Linguagem) - Universidade Estadual de Londrina, Londrina, 2011. RICHARDS, J. C.; LOCKHART, C. Reflective teaching in second language classrooms. Cambridge: Cambridge University Press, 1994.

SANTOS, V. C. A formação de professores em comunidades de prática: o caso de um grupo de professores de química em formação inicial. 2015. 451 f. Tese (Doutorado em Ciências) - Universidade de São Paulo, São Paulo, 2015.

SCHÖN, D. The reflective practitioner: how professionals think in action. New York: Basic Books, 1983.

STEIN, A. Representações de formadores de professores de inglês no contexto do PDE-PR. 2015. 90 f. Dissertação (Mestrado em Estudos da Linguagem) - Universidade Estadual de Londrina, Londrina, 2015.

WALLACE, M. J. Training foreign language teachers: a reflective approach. Cambridge: Cambridge University Press, 1991.

WENGER, E. Communities of practice: learning, meaning and identity. Cambridge: Cambridge University Press, 1998a.

WENGER, E. Communities of practice: learning as a social system. The Systems Thinker, Colorado, v. 9, n. 5, p. 1-10, 1998b.

WILLIAMS, M. Motivation in foreign and second language learning: an interactive perspective. Educational and Child Psychology, San Francisco, v. 11, p. 77-84, 1994.

ZEICHNER, K.; LISTON, D. Reflective teaching: an introduction. New York: Routledge, 1996.

Data de submissão: 23/02/2017. Data de aprovação: 19/05/2017. 